\title{
Green tea halts progression of cardiac transthyretin amyloidosis: an observational report
}

\author{
Arnt V. Kristen · Stephanie Lehrke • Sebastian Buss • Derliz Mereles • Henning Steen • Philipp Ehlermann • \\ Stefan Hardt • Evangelos Giannitsis - Rupert Schreiner - Uwe Haberkorn • Philipp A. Schnabel • \\ Reinhold P. Linke • Christoph Röcken • Erich E. Wanker • Thomas J. Dengler · Klaus Altland • \\ Hugo A. Katus
}

Received: 8 December 2011 / Accepted: 19 April 2012/Published online: 15 May 2012

(C) The Author(s) 2012. This article is published with open access at Springerlink.com

\begin{abstract}
Background Treatment options in patients with amyloidotic transthyretin (ATTR) cardiomyopathy are limited. Epigallocatechin-3-gallate (EGCG), the most abundant catechin in green tea (GT), inhibits fibril formation from several amyloidogenic proteins in vitro. Thus, it might also halt progression of TTR amyloidosis. This is a singlecenter observational report on the effects of GT consumption in patients with ATTR cardiomopathy.

Methods 19 patients with ATTR cardiomyopathy were evaluated by standard blood tests, echocardiography, and cardiac MRI $(n=9)$ before and after consumption of GT and/or green tea extracts (GTE) for 12 months.
\end{abstract}

K. Altland, H. A. Katus contributed equally to this work.

Electronic supplementary material The online version of this article (doi:10.1007/s00392-012-0463-z) contains supplementary material, which is available to authorized users.

A. V. Kristen $(\bowtie) \cdot$ S. Lehrke $\cdot$ S. Buss $\cdot$ D. Mereles

H. Steen · P. Ehlermann $\cdot$ S. Hardt $\cdot$ E. Giannitsis .

T. J. Dengler $\cdot$ H. A. Katus

Department of Cardiology, Angiology, and Respiratory

Medicine, University Hospital Heidelberg, Im Neuenheimer

Feld 410, 69120 Heidelberg, Germany

e-mail: Arnt_Kristen@med.uni-heidelberg.de

\section{R. Schreiner}

Laboratory of Dr. Limbach and Associates,

Im Breitspiel 15, 69126 Heidelberg, Germany

U. Haberkorn

Department of Nuclear Medicine, University of Heidelberg, Im Neuenheimer Feld 400, 69120 Heidelberg, Germany

P. A. Schnabel

Institute of Pathology, Heidelberg University, Im Neuenheimer

Feld 220/221, 69120 Heidelberg, Germany
Results Five patients were not followed up for reasons of death $(n=2)$, discontinuation of GT/GTE consumption $(n=2)$, and heart transplantation $(n=1)$. After 12 months no increase of left ventricular (LV) wall thickness and LV myocardial mass was observed by echocardiography. In the subgroup of patients evaluated by cardiac MRI a mean decrease of LV myocardial mass $(-12.5 \%)$ was detected in all patients. This was accompanied by an increase of mean mitral annular systolic velocity of $9 \%$ in all 14 patients. Total cholesterol $(191.9 \pm 8.9$ vs. $172.7 \pm 9.4 \mathrm{mg} / \mathrm{dL} ; \quad p<0.01)$ and LDL cholesterol $(105.8 \pm 7.6$ vs. $89.5 \pm 8.0 \mathrm{mg} / \mathrm{dL} ; p<0.01)$ decreased significantly during the observational period. No serious adverse effects were reported by any of the participants. Conclusions Our observation suggests an inhibitory effect of GT and/or GTE on the progression of cardiac amyloidosis. We propose a randomized placebo-controlled investigation to confirm our observation.

\section{R. P. Linke}

Reference Center of Amyloid Diseases, amYmed,

Am Klopferspitz 19, 82152 Martinsried, Germany

C. Röcken

Institute of Pathology, Christian-Albrechts-University,

Arnold-Heller-Straße 3/14, 24105 Kiel, Germany

\section{E. E. Wanker}

Max Delbrück Center for Molecular Medicine,

AG Neuroproteomics, 13092 Berlin, Germany

K. Altland

Institute of Human Genetics, Giessen University, Schlangenzahl 14, 35392 Giessen, Germany 
Keywords Cardiomyopathy Green tea

Transthyretin-derived amyloidosis

Epigallocatechin-3-gallate

\section{Introduction}

Cardiac ATTR amyloidosis is observed as the predominant manifestation associated with distinct mutations in the TTR gene also known as familial amyloid cardiomyopathy (FAC) [1] and represents the major complication in patients of advanced age with familial amyloid polyneuropathy (FAP) [2]. Wild-type TTR (senile systemic amyloidosis, SSA) has been found in $25 \%$ of post-mortem cardiac biopsies from patients older than 85 years [3]. Pre-mortem diagnosis is rare, but prevalence appears to be underestimated. By routine scintigraphic skeletal imaging SSA has been detected in 2 males among 374 consecutive admissions older than 60 years, indicating a prevalence of about $0.5 \%$ [4].

Without treatment both hereditary and non-hereditary forms of cardiac ATTR amyloidosis are progressing and fatal after several years. Patient's prognosis mostly depends on the extent of cardiac involvement. Despite that therapeutic options for patients with light-chain amyloidosis have been ameliorated during the past years [5], treatment concepts for patients with advanced cardiac involvement in TTR amyloidosis are still limited. Liver transplantation has become an accepted causative treatment to stop the hepatic production of variant TTR [6] in FAP and FAC patients, but progression of cardiac amyloid deposition has been observed rather frequently after liver transplantation [7]. Patients with advanced cardiac amyloidosis are deemed ineligible for this approach due to high treatment-related mortality. Liver transplant has no therapeutic effect in SSA patients. Heart transplantation remains the only therapeutic option for advanced cardiac TTR amyloidosis but is limited to patients at age $<65$ years.

Assuming a prevalence of $0.5 \%$ for clinically relevant cardiac ATTR amyloidosis in the growing elderly population ( $>60$ years) there is a high need for novel effective preventive and therapeutic measures against this otherwise fatal disease. Experimental studies evaluated the suppression of hepatic synthesis of TTR by antisense oligonucleotids [8]. Several small compounds, e.g. non-steroidal anti-inflammatory drugs or derivatives [9], flavonoids [10], xanthones of plant origin [11], and sulfite [12] have been suggested for treatment of ATTR amyloidosis by inhibiting TTR tetramer dissociation and/or impairing amyloid fibril formation. Recently, Tafamidis (Fx-1006A), a strong inhibitor of TTR tetramer dissociation has been approved for the treatment of patients with FAP stage I (http://www.ema.europa.eu/ema/index.jsp?curl= pages/medicines/human/medicines/002294/human_med_0 01498.jsp\&mid=WC0b01ac058001d124).
Laboratory studies have shown that human TTR is rather stable at physiological $\mathrm{pH} 7.4$ but tends to denature at $\mathrm{pH}$ 6.5-7, levels observed under inflammatory or ischemic conditions, indicating that prevention of such conditions could help to reduce the risk for TTR to denature and become converted into amyloid [13]. Recent in vitro experiments have shown that $50 \mu \mathrm{M}$ epigallocatechin-3-gallate (EGCG), the most abundant catechin in green tea (GT), efficiently inhibits fibril formation from amyloid B-protein, $\alpha$-synucleine [14], and TTR [15] and converts existing fibrils into non-fibril conformers [16]. In a FAP transgenic mouse model a reduction of amyloid deposition was observed after treatment with $100 \mathrm{mg}$ EGCG per $\mathrm{kg}$ body weight per day over a period of 6 weeks [17]. A retired member of our faculty (Dr. W. Hunstein), observed a $25 \%$ decrease of the LV wall thickness after having consumed 1.5-2 L of GT daily over 11 months $[18,19]$. According to manufacturer information the green tea used by Hunstein contained about $350 \mathrm{mg}$ EGCG per liter when brewed for $5 \mathrm{~min}$ at $100{ }^{\circ} \mathrm{C}$. A decrease of $\mathrm{LV}$ wall thickness $>2 \mathrm{~mm}$ was observed in $11 \mathrm{AL}$ amyloidosis patients with history of regular GT consumption [20]. The initial in vitro studies by Ehrnhoefer et al. [14] as well as the personal in vivo observation of Hunstein [18] stimulated our trial to reproduce Hunstein's observation in patients with cardiac ATTR amyloidosis.

\section{Methods}

The present cohort at the Heidelberg Amyloidosis Center consisted of 19 patients (15 males, 4 females; mean age $66.3 \pm 2.0$ years $)$ with hereditary $(n=10,53 \%)$ or nonhereditary SSA $(n=9,47 \%)$ cardiac ATTR amyloidosis and compensated heart failure. Patients were observed over a period of 12 months while consuming GT and/or GTE. Routine medication was continued during this period. The observation was approved by the institutional Ethics Committee of the University of Heidelberg and complied with the Declaration of Helsinki [21].

All patients had biopsy-proven ATTR confirmed by green birefringence of Congo red-stained sections viewed in polarized light and subsequent immunohistochemical classification of the amyloid deposits [22, 23]. They were screened for amyloidogenic TTR variants by isoelectric focusing of plasma TTR and by sequencing of genomic DNA [24]. Clonal light-chains were examined by serum/ urine immunofixation electrophoresis and a serum-free light-chain test. Monoclonality was excluded in all patients. All patients had increased tracer retention in the heart by ${ }^{99 \mathrm{~m}}$ Tc DPD scintigraphy (Fig. 1) indicating cardiac ATTR depositions [25, 26]. 


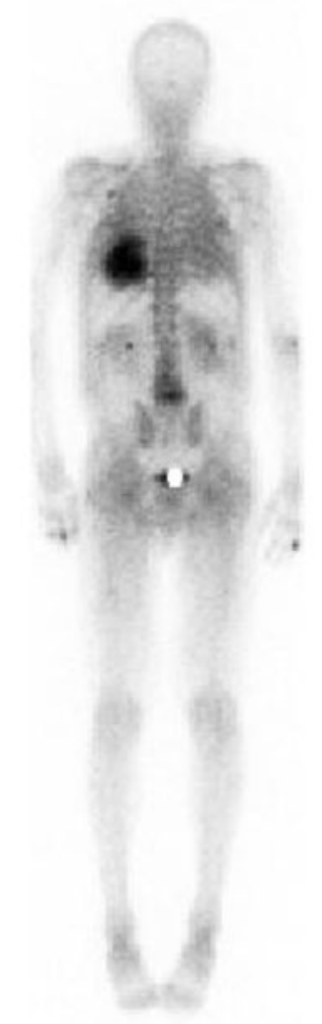

\section{left dorsal right right ventral left}

Fig. 1 Whole body scintigraphy for visualization of cardiac transthyretin amyloid Cardiac tracer uptake obtained $3 \mathrm{~h}$ after application of $736 \mathrm{MBq}$ technetium-99 m 3,3-diphosphono-1,2-propanodicarboxylic acid $\left({ }^{99 \mathrm{~m}} \mathrm{Tc}-\mathrm{DPD}\right)$ indicating cardiac ATTR amyloid deposition

In addition to cardiac involvement patients with hereditary TTR amyloidosis had clinical evidence for involvement of gut $(n=4 ; 40 \%)$, and/or peripheral nerves $(n=8 ; 80 \%)$. The main clinical symptoms at study entry were polyneuropathy in six patients and exertional dyspoea in eight patients. Mean functional heart failure class according to New York Heart Association was $2.0 \pm 0.2$. Four patients $(40 \%)$ with hereditary amyloidosis had orthotopic liver transplantation prior to study inclusion.

After having received written informed consent for participation in this observational project the patients were evaluated by standard blood tests, echocardiography with Doppler studies, and cardiac magnetic resonance imaging (cMRI). Follow-up controls were performed by clinical investigation at the Heidelberg Amyloidosis Center 6 and 12 months after study inclusion.

Echo- and electrocardiography

All transthoracic echocardiograms were performed according to a routine protocol using commercially available ultrasound diagnostic systems (Vivid 7, GE Healthcare, Milwaukee, WI, USA) by experienced investigators. Three cardiac cycles were stored in cine loop format for offline analysis. In patients who were in atrial fibrillation five consecutive beats were averaged. Offline analysis of echocardiography examinations of both cohorts were conducted on a commercially available workstation (Centricity Cardiology CA1000 2.0, GE Medical Systems, Milwaukee, WI, USA) independently by three expert investigators blinded by time point. M-mode or 2D recordings were analyzed for diastolic interventricular septum thickness (IVS), diastolic posterior wall thickness, end-diastolic and end-systolic left ventricular (LV) cavity diameter, LV systolic and longitudinal function, and pericardial effusion [27]. Left ventricular mass was calculated by the Devereux formula [28]. LV function was assessed according to standard definitions [29] and was considered markedly impaired at $<40 \%$ by the biplane Simpson method (2D/4D). LV longitudinal function was assessed by mitral and tricuspid annular plane systolic excursion from the apical 4-chamber view by measuring the maximum excursion of the lateral site of the annulus after ventricular systole by M-mode imaging. Pulsed-wave Doppler tissue imaging of the mitral annulus was done using a standard spectral Doppler sample volume gate length of $0.17 \mathrm{~cm}$. The sample volume was placed on the lateral mitral annulus in the apical four-chamber view to measure systolic velocity.

\section{Cardiac magnetic resonance imaging}

CMRI was performed on a 1.5-T whole body MRI scanner (Achieva Intera1 Philips Medical Systems, Best, The Netherlands) equipped with a five-element cardiac receiver coil according to a protocol that has been described in detail previously [30]. Resting LV function was determined by cine images using a segmented k-space balanced fast-field-echo sequence (Steady-State-Free-Precession, matrix $=160 / 256$, sense-factor $=2$, flip angle $=60^{\circ}$, slice thickness/gap $=$ $8 / 2 \mathrm{~mm}$ ) in contiguous short axes covering the whole left ventricle from base to apex as well as two, three, and chamber views in anatomically correct heart axes. Data analysis was carried out on a commercially available cMRI workstation (Philips Viewforum, Version 3.4, Best, The Netherlands) by three independent observers blinded by time point. LV enddiastolic and endsystolic volumes with resulting ejection fraction as well as myocardial mass in diastole were determined from short axes by manual delineation of endocardial and epicardial borders excluding papillary muscles.

Dosage of green tea and green tea extract

The protocol followed that of Hunstein [18]. All patients were asked for a daily intake of approximately $500-700 \mathrm{mg}$ 
EGCG either by drinking $1.5-2 \mathrm{~L}$ of GT per day $(10 \mathrm{~g} / \mathrm{L}$ Green Darjeeling, FTGFOP1, Teekampagne Projektwerkstatt $\mathrm{GmbH}$, Berlin, Germany; brewed 3-5 min at $100{ }^{\circ} \mathrm{C}$, and containing about $340 \mathrm{mg} \mathrm{EGCG/L;} \mathrm{[31])} \mathrm{or} \mathrm{by}$ the intake of caffeine-free GTE capsules (praevent-loges ${ }^{\circledR}$, Dr. Loges + Co. GmbH, Winsen/Luhe, Germany, containing $300 \mathrm{mg}$ GTE with $75 \mathrm{mg}$ EGCG/capsule). Patients were asked to document in a protocol their daily GT and/or GTE consumption as well as any adverse effects. This protocol was used to calculate the mean daily EGCG intake during the observational period [(total GT (in L) $\times 340 \mathrm{mg} / \mathrm{L} \times$ total number of GTE capsules $\times 75 \mathrm{mg}$ )/days of observation].

\section{Quantification of plasma EGCG levels}

Blood samples were collected in EDTA-containing tubes. As EGCG rapidly changes its structure above $\mathrm{pH} 7$, binds to proteins, and becomes oxidized, the blood samples were immediately transferred to an ice bath and the plasma was separated from the cellular fraction by centrifugation at $4{ }^{\circ} \mathrm{C}$. One $\mathrm{ml}$ of each plasma sample was mixed with $50 \mu \mathrm{L}$ of an ascorbate-EDTA solution [0.4 M $\mathrm{NaH}_{2} \mathrm{PO}_{4}$ buffer containing $20 \%$ ascorbic acid and $0.1 \%$ EDTA (pH 3.6)] and stored at $-20{ }^{\circ} \mathrm{C}$ until analysis. The EGCG levels were measured via LCMSMS (liquid chromatography equipped with a triple quadruple mass spectrometer). In short, $100 \mu \mathrm{L}$ of the stabilized plasma was acidified with $20 \mu \mathrm{L} 5 \mathrm{~N} \mathrm{HCl}$ and extracted twice with ethyl acetate. The organic phase was evaporated and resolved in $300 \mu \mathrm{L}$ of a solution containing two volumes of a $20-\mathrm{mM}$ ammonium acetate buffer $\mathrm{pH} 3.6$ and 1 volume methanol. The separation was performed on a C18 Reversed-Phase Column with a gradient of $20 \mathrm{mM}$ ammonium acetate against methanol. The transitions monitored in the mass selective detector under negative modus were 457 (precursor Ion) to 125 product Ion, 457 (precursor Ion) to 169 product Ion (qualifier), and as internal standard 319 (precursor Ion) to 191 product Ion.

\section{Statistical analysis}

Continuous data were expressed as median and range. Categorical variables were expressed as absolute numbers and percentages. Differences between the nonparametric, continuous parameters assessed at study inclusion and at 12-month follow-up visit were compared by the Wilcoxon rank-sum test. $p<0.05$ was considered statistically significant. Statistical analyses were performed using StatView (Version 5.0, SAS Institute, Cary, NC, USA).

\section{Results}

Patients

Of a total of 19 examined patients five patients were lost during the study period either due to death $(n=2)$, discontinuation of green tea consumption $(n=2)$, or heart transplantation $(n=1)$. All study patients $(n=14)$ were assessed by echocardiography. One patient died 1 month after study inclusion due to cardiac failure; the second death occurred after a 5-month stay at the intensive care unit with prolonged artificial ventilation, hemofiltration, recurrent infections, and finally death due to multi-organ failure after drainage of a retroperitoneal hematoma. Due to prior placement of cardiac pacemaker $(n=2)$, internal defibrillator $(n=1)$, orthopedic prosthesis $(n=1)$, or claustrophobia $(n=1)$ cMRI images were obtained only from 9 of the 14 study patients. The clinical state of the 14 study patients as well as oral heart failure medication remained unchanged during the observation period. None of the patients was hospitalized due to cardiac decompensation. The main clinical demographics of the 14 patients with 12-month follow-up are shown in Table 1. Detailed data for all 14 patients at the beginning and the end of the observation period are given in Table $1 \mathrm{~S}$ (Supplemental information).

Quantification of plasma EGCG levels, cholesterol, and NT-proBNP

All patients documented their daily intake of GT/GTE. According to the protocols mean oral EGCG intake was calculated as $547 \pm 49 \mathrm{mg}$ per day. Individual mean daily EGCG intake is shown in the supplementary table. No serious adverse effects were reported. Mean EGCG plasma level after $12 \mathrm{~h}$ of GT/GTE abstinence was $48 \pm 14 \mu \mathrm{g} / \mathrm{L}$ $(0.1 \pm 0.03 \mu \mathrm{M})$. Mean plasma EGCG level $2 \mathrm{~h}$ after intake of $150 \mathrm{mg}$ EGCG as GTE (2 capsules) was $253 \pm 68 \mu \mathrm{g} / \mathrm{L} \quad(0.55 \pm 0.15 \mu \mathrm{M}$, range $0.1-1.8 \mu \mathrm{M})$. During the observation period mean total cholesterol and LDL cholesterol decreased from $191.9 \pm 8.9$ to $172.7 \pm$ $9.4 \mathrm{mg} / \mathrm{dL}(p<0.01)$ and from $105.8 \pm 7.6$ to $89.5 \pm$ $8.0 \mathrm{mg} / \mathrm{dL}(p<0.01)$, respectively (see Fig. 2a, b). Mean HDL cholesterol remained unchanged $(58.9 \pm 3.9$ to $55.4 \pm 4.6 \mathrm{mg} / \mathrm{dL}(p<0.01)$.

Echocardiography analysis

During 12 months of GT/GTE intake a statistically significant decrease by $6.5 \%$ of the thickness of IVS was observed (Fig. 3a). Thickness of IVS decreased in 12/14 patients (86\%); in 4 patients by $\geq 2 \mathrm{~mm}$, remained unchanged in 1 patient $(7 \%)$ and increased $2 \mathrm{~mm}$ in 1 
Table 1 Clinical demographics of the patients included in the study

\section{$F U$ follow-up}

a Body weight $(\mathrm{kg}) /$ body height $\left(\mathrm{m}^{2}\right) \times$ plasma albumin $(\mathrm{d} / \mathrm{L})$

\begin{tabular}{|c|c|c|}
\hline Clinical demographics & $\begin{array}{l}\text { All patients }(n=14) \\
\text { Mean } \pm \text { SEM or number }(\%)\end{array}$ & $\begin{array}{l}\text { Patients studied by cMRI }(n=9) \\
\text { Mean } \pm \text { SEM or number }(\%)\end{array}$ \\
\hline Age (years) & $66 \pm 3$ & $68 \pm 2$ \\
\hline Gender male/female & $10(71 \%) / 4(29 \%)$ & $7(78 \%) / 2(22 \%)$ \\
\hline Height $(\mathrm{cm})$ & $169 \pm 2$ & $171 \pm 2$ \\
\hline Weight (kg) & $71 \pm 3$ & $72 \pm 3$ \\
\hline Modified body mass index ${ }^{a}$ & $1,080 \pm 46$ & $1,084 \pm 45$ \\
\hline Patients with variant TTR & $8(57 \%)$ & $5(56 \%)$ \\
\hline Val20Ile & 0 & 0 \\
\hline Val30Met & $5(36 \%)$ & $4(44 \%)$ \\
\hline Gly47Glu & $1(7 \%)$ & 0 \\
\hline Gly47Ala & $1(7 \%)$ & 0 \\
\hline Ile107Val & $1(7 \%)$ & $1(12 \%)$ \\
\hline Patients with SSA & $6(43 \%)$ & $4(44 \%)$ \\
\hline Orthotopic liver transplant & 2 & 1 \\
\hline Pacemaker placement & 2 & - \\
\hline Defibrillator placement & 1 & - \\
\hline Orthopedic prosthesis & 1 & - \\
\hline
\end{tabular}
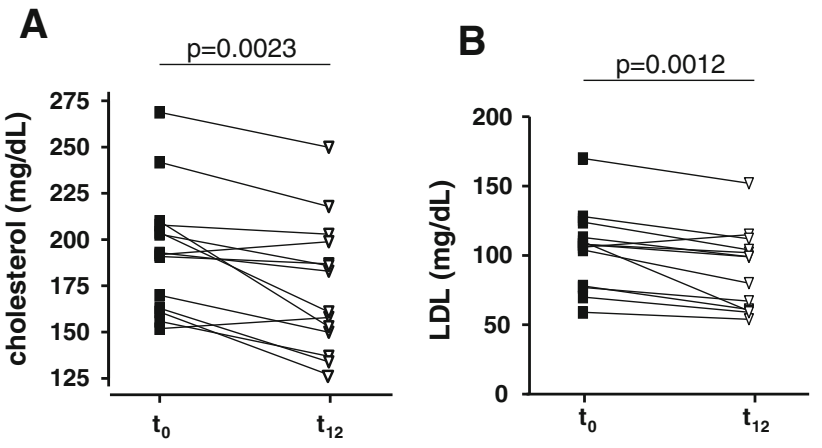

Fig. 2 Changes of lipid profile during the study period Total cholesterol (a) and LDL cholesterol (b) plasma levels of patients with TTR amyloidosis before $\left(t_{0}\right)$ and after 12 months $\left(t_{12}\right)$ of green tea consumption

patient $(7 \%)$. Mean thickness of the posterior wall did not change during the study period (Fig. 3b). A decrease of the posterior wall thickness was observed in 10/14 patients (71\%; $\geq 2 \mathrm{~mm}$ in 2 patients), and an increase of less than $2 \mathrm{~mm}$ was detected in 4/14 patients (29\%). Mean LV myocardial mass did not increase during the observational period of GT/GTE intake (Fig. 3c). In detail, LV myocardial mass decreased in 9/14 (64\%) patients, increased in $3 / 14(21 \%)$ patients, and remained unchanged in $2 / 14$ (14\%) patients. A significant improvement of the mean systolic velocity of the lateral mitral annulus was observed (improved in 10/14 patients (71\%); diminished in $4 / 14$ (14\%) patients; Fig. 3d). More detailed echocardiographic data are shown in Table 1S (Supplemental information). Inter-observer variability of echocardiography was $7.6 \%$.
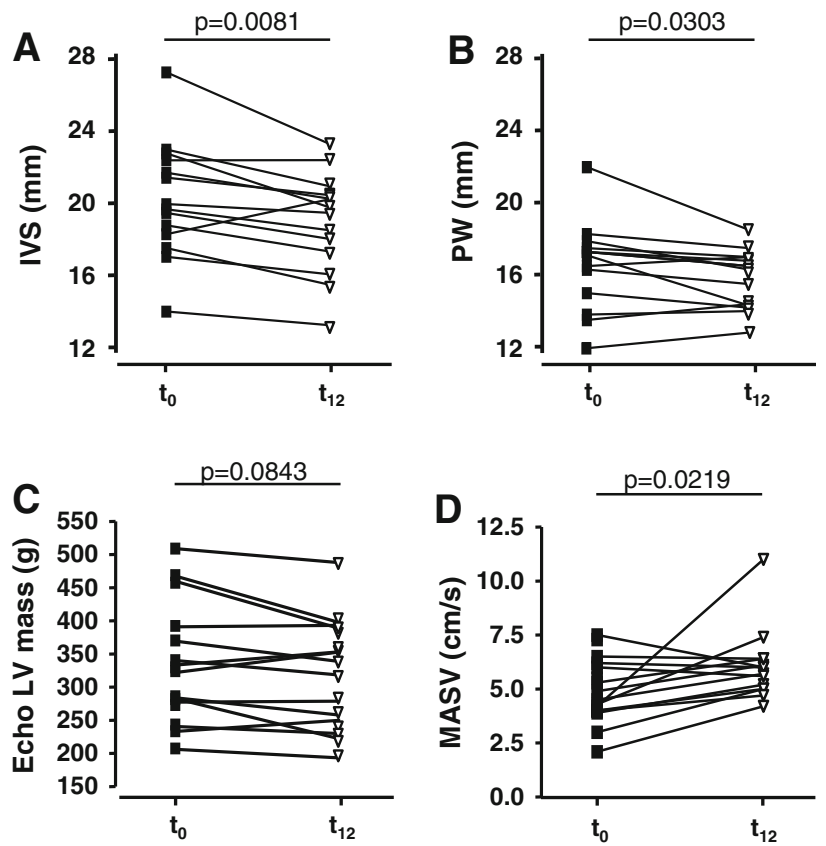

Fig. 3 Echocardiographic changes during the study period (a) Interventricular septum thickness, (b) posterior wall thickness, (c) left ventricular myocardial mass, and (d) systolic velocity of the lateral mitral annulus (MASV) assessed by echocardiography in patients with TTR amyloidosis before $\left(t_{0}\right)$ and after 12 months $\left(t_{12}\right)$ of green tea consumption

cMRI analysis

Clinical characteristics of the subgroups of patients assessed by cMRI $(n=9)$ did not differ from the whole patient cohort (Table 1). We observed a significant average 


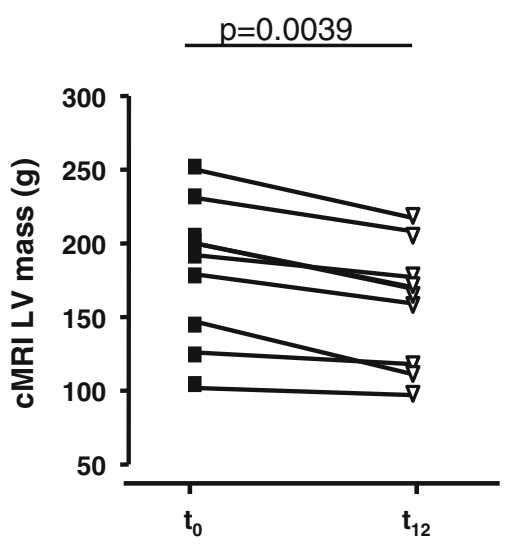

Fig. 4 MRI changes during the study period left ventricular (LV) myocardial mass assessed by cardiac MRI in patients with TTR amyloidosis before $\left(t_{0}\right)$ and after 12 months $\left(t_{12}\right)$ of green tea consumption

decline of LV myocardial mass by $12.5 \%$ (Fig. 4). In none of the patients an increase of LV myocardial mass was observed. LV ejection fraction remained unchanged (56.7 \pm 4.7 vs. $57.2 \pm 3.7 \%$; ns). Detailed cMRI findings are shown in Table 1S (Supplemental information). Interobserver variability of MRI was $4.2 \%$.

\section{Discussion}

This is the first single center observation of myocardial parameters during daily consumption of EGCG as GT or GTE for 1 year in patients with cardiac ATTR amyloidosis. No progression of cardiac wall thickness and mass as indicators of ATTR amyloid deposition was observed in these patients during the 1-year observation period. No serious adverse effects were reported.

EGCG as the most abundant catechin in GT has been claimed to prevent all-cause cardiovascular morbidity and mortality [32]. These effects might in part be caused by its lipid lowering effects [33] as observed in all patients of the present study. There are reports indicating that GT or oral supplements of GTE marketed for weight loss may cause serious side effects including acute liver toxicity [34]. In our patients hepatic function remained unchanged during the observation period.

Orthotopic liver transplantation is currently the only available causative treatment of familial amyloid polyneuropathy and/or cardiomyopathy as it eliminates the production of the variant amyloid precursor protein [35] and induces a marked regression (or even disappearance) of amyloid in abdominal fat [36]. In some patients with pre-existing cardiac involvement, progression of amyloid apposition was not halted due to continued deposition of amyloid aggregates from normal TTR aggregates [37-39].
No therapeutic effect of liver transplantation has been observed in SSA patients.

Laboratory experiments have shown that EGCG binds to recombinant wild-type as well as variant TTR tetramers at three sites different from the thyroxine binding site $[15,40$, 41]. A stabilizing effect adding to that of the thyroid hormone was observed. Using a transgenic mice model Ferreira et al. [17] demonstrated an inhibitory effect of EGCG on amyloid deposition as well as a degrading effect on preformed amyloid fibrils. The described data, however, were achieved using a 10-100 fold excess of EGCG over TTR, far above the observed plasma concentration $(0.5 \mu \mathrm{M})$ and applied doses $(1 \mathrm{mmol})$ of EGCG in this trial. However, using $100 \mathrm{nM}$ fibrillar $\alpha$-synucleine Bieschke et al. [16] found significant aggregate-bound EGCG at concentrations between $20 \mathrm{nM}$ and $1 \mu \mathrm{M}$ (apparent dissociation constant $0.1 \mu \mathrm{M}$ ). Using isothermal titration calorimetry (ITC) Ferreira et al. [15] found a dissociation constant of $0.4 \mu \mathrm{M}$ for the interaction of non-denaturated TTR and EGCG.

Progression of left ventricular wall mass within a time span of 1 year was observed in a different group of untreated patients with mutant ATTR and cardiac involvement [42]. It is well known that LV mass varies within the mutation involved and with age at onset of the disease [43]. Survival of patients with cardiac TTR amyloidosis appears to be much better than survival of patients with light-chain amyloidosis [44, 45]. There is, however, a wide variation of 5-year survival rates for patients with different TTR mutations (30-55\%) and among patients with wild-type TTR amyloidosis (40-75 \%) [44-47]. The patients in Benson's study group [42] were about 12 years younger than the patients of our cohort and included individuals with mutations different from those of our patients. Therefore, the results of Benson's and our present study may not be comparable in a clean scientific approach. The lack of an appropriate control group will affect final conclusion from the present observation.

Cardiac MRI is the gold standard for cardiac morphology and function due to its high reproducibility and low interobserver variability [48] and has been used as an endpoint in several interventional studies, either for reduction of LV myocardial mass, e. g. arterial hypertension [49], and Fabry's disease. Fabry [50] or for quantification of scar size after TASH procedure in hypertrophic cardiomyopathy [51]. In the present cohort the reduction of LV myocardial mass by cMRI was more pronounced than the blinded interobserver variability, but appears to be slow, as observed with enzyme replacement therapy in patients with Fabry's disease [52-54]. LV wall mass was found unchanged as assessed by echocardiography, possibly due to methodological limitations and limited imaging quality in some patients. However, improved mitral annulus velocity was observed as the most accurate diastolic measure to detect 
early left ventricular dysfunction in patients with $\mathrm{AL}$ amyloidosis [55] and to differentiate restrictive cardiomyopathy from pericarditis constrictiva [56]. In comparison with our echocardiographic data the absolute values of $\mathrm{LV}$ myocardial mass were much lower in the present study when assessed by cMRI in comparison with echocardiography. This reflects a well-known phenomenon [57] that was recently shown in a report of patients with hereditary amyloidosis [42, 52]. A possible explanation could be the inclusion of right ventricular trabecula in the measurement of the basal septal wall by echocardiography, especially in patients with massive hypertrophy.

This study was initiated to reproduce Hunstein's in vivo observation in ATTR cardiomyopathy patients. A decrease of about $25 \%$ of left ventricular wall thickness as reported by Mereles et al. [19] was observed in none of the present patients. As Hunstein suffered from AL amyloidosis and had chemotherapy before he started his tea experiment, the clinical courses of the two different types of disease are not comparable.

Tafamidis, a novel specific inhibitor of TTR tetramer dissociation has been evaluated in a prospective placebocontrolled phase II/III clinical trial in FAP patients and found to reduce the progression of polyneuropathy in the majority of patients (http://www.ema.europa.eu/ema/index. jsp?curl=pages/medicines/human/medicines/002294/human med_001498.jsp\&mid=WC0b01ac058001d124). The binding sites of EGCG have been described to be different from those of known inhibitors for TTR tetramer dissociation [15]. We conclude that due to different modes of interaction, a combined treatment with GT/GTE and tafamidis may complement each other and increase the observed beneficial effects against the major problems of ATTR amyloidosis patients.

Plasma levels of EGCG $2 \mathrm{~h}$ after intake of $150 \mathrm{mg}$ EGCG ranged from 44 to $840 \mu \mathrm{g} / \mathrm{L}$. The individual plasma level of EGCG may be affected by the method of tea preparation, the instability under physiologic conditions, differential gastrointestinal absorption, and the modification by hepatic enzymes [58]. Although we asked our patients to follow a protocol of GT preparation and to use GTE from a single manufacturer, significant uncontrollable modifiers of EGCG bioavailability appear to remain. The endpoint of our study, i.e. change of LV myocardial mass, may be affected by components of GT and GTE other than EGCG bioavailability. We assume that this and a still unknown variability of the interindividual of EGCG might have influence on the observed treatment effects. Adjustment of the individual EGCG plasma levels by appropriate variation of dose or by supporting an increased intestinal EGCG uptake by additional consumption of piperine and ascorbic acid [59] could help ameliorate the effect of treatment. The daily intake dose of EGCG was restricted by the initial design of this study, i.e. to reproduce Hunstein's in vivo experiment in ATTR cardiomyopathy patients. The lack of an appropriate control collective taking placebo is due to the small number of available patients with ATTR cardiomyopathy in this country. Furthermore, the rather widespread knowledge of the results of Hunstein's experiment among affected patients resulted in a very low acceptance to renounce on the use of a possible beneficial effect of GT/ GTE available to everybody. For ATTR cardiomyopathy being an orphan disease we also were not able to create a control group from safe retrospective data.

GT has been proven beneficial by consumption for several thousands of years by many millions of individuals and is part of the daily routine in the Far East without any reported side-effects. Therefore, its use may be of interest for FAC patients and those at age beyond 65 years with no access to heart transplantation. Randomized, placebo-controlled investigations with longer study periods and larger samples of patients should confirm the results of this observation, determine the optimal dosage of GT/GTE for treatment, and identify undesirable side effects.

Acknowledgments We appreciate the pilot in vivo experiment of Prof. Dr. Werner Hunstein affected by AL $\lambda$ amyloidosis which was encouraging for many patients with AL amyloidosis and stimulated us to reproduce his observation in patients with ATTR amyloidosis. We acknowledge the assistance of Gerda Baumann. Christoph Bode (Department of Cardiology, University of Freiburg, Germany), Carsten Hehlert-Friedrich (Department of Neurology, Kreiskrankenhaus Krumbach, Germany), Michael Schulte-Hermes (Department of Cardiology, Helios Klinikum Wuppertal, Germany), Kambis Mashayekhi (Department of Cardiology, Herz- und Gefäßklinik GmbH Bad Neustadt a. d. Saale, Germany), Christian Bamberg (Center of Psychiatry, Psychotherapy and Neurology, Rhein-Mosel-Fachklinik Andernach, Germany) as well as M. Langer (Department of Cardiology, Robert-Bosch-Krankenhaus Stuttgart, Germany) are acknowledged for their most helpful support to include patients in this study. This work was supported financially by Peter Waldmann Amyloidose-Stiftung (Küssnacht, Switzerland). Capsules of GTE were a gift from Dr. Loges + Co. GmbH (Winsen/Luhe, Germany) and GT was provided by Projektwerkstatt GmbH (Berlin, Germany). None of them participated in the design and data analysis of the present study data. This was exclusively made by the authors.

\section{Conflict of interest None.}

Open Access This article is distributed under the terms of the Creative Commons Attribution License which permits any use, distribution, and reproduction in any medium, provided the original author(s) and the source are credited.

\section{References}

1. Ikeda S (2004) Cardiac amyloidosis: heterogenous pathogenic backgrounds. Intern Med 43:1107-1114

2. Suhr OB, Lindqvist $P$, Olofsson BO, Waldenstrom A, Backman C (2006) Myocardial hypertrophy and function are related to age at onset in familial amyloidotic polyneuropathy. Amyloid 13:154-159 
3. Cornwell GG III, Murdoch WL, Kyle RA, Westermark P, Pitkanen P (1983) Frequency and distribution of senile cardiovascular amyloid. A clinicopathologic correlation. Am J Med 75:618-623

4. Puille M, Altland K, Linke RP, Klett R, Bauer R (2002) Tc99 m-DPD scintigraphy in transthyretin-type amyloidosis. Presented at the 5th Internat. Symposium on Familial Amyloidotic Polyneuropathy and Other Related Disorders, Sept 25-27, 2002 Matsumoto, Japan

5. Cibeira MT, Sanchorawala V, Seldin DC, Quillen K, Berk JL, Dember LM, Segal A, Ruberg F, Meier-Ewert H, Andrea NT, Sloan JM, Finn KT, Doros G, Blade J, Skinner M (2011) Outcome of AL amyloidosis after high-dose melphalan and autologous stem cell transplantation: long-term results in a series of 421 patients. Blood 118:4346-4352

6. Okamoto S, Wixner J, Obayashi K, Ando Y, Ericzon BG, Friman S, Uchino M, Suhr OB (2009) Liver transplantation for familial amyloidotic polyneuropathy: impact on Swedish patients' survival. Liver Transpl 15:1229-1235

7. Hornsten R, Wiklund U, Olofsson BO, Jensen SM, Suhr OB (2004) Liver transplantation does not prevent the development of life-threatening arrhythmia in familial amyloidotic polyneuropathy, Portuguese-type (ATTR Val30Met) patients. Transplantation 78:112-116

8. Benson MD, Kluve-Beckerman B, Zeldenrust SR, Siesky AM, Bodenmiller DM, Showalter AD, Sloop KW (2006) Targeted suppression of an amyloidogenic transthyretin with antisense oligonucleotides. Muscle Nerve 22:609-618

9. Baures PW, Oza VB, Peterson SA, Kelly JW (1999) Synthesis and evaluation of inhibitors of transthyretin amyloid formation based on the non-steroidal anti-inflammatory drug, flufenamic acid. Bioorg Med Chem 7:1339-1347

10. Lueprasitsakul W, Alex S, Fang SL, Pino S, Irmscher K, Kohrle J, Braverman LE (1990) Flavonoid administration immediately displaces thyroxine (T4) from serum transthyretin, increases serum free $\mathrm{T} 4$, and decreases serum thyrotropin in the rat. Endocrinology 126:2890-2895

11. Maia F, Almeida MR, Gales L, Kijjoa A, Pinto MM, Saraiva MJ, Damas AM (2005) The binding of xanthone derivatives to transthyretin. Biochem Pharmacol 70:1861-1869

12. Altland K, Winter P, Saraiva MJ, Suhr O (2004) Sulfite and base for the treatment of familial amyloidotic polyneuropathy: two additive approaches to stabilize the conformation of human amyloidogenic transthyretin. Neurogenetics 5:61-67

13. Altland K, Richardson SJ (2009) Histidine 31: The Achilles' Heel of human transthyretin. Microheterogeneity is not enough to understand the molecular causes of amyloidgenicity. In: Richardson SJ, Cody V (eds) Recent advances in transthyretin evolution, structure and biological function. Springer, BerlinHeidelberg, pp 201-214

14. Ehrnhoefer DE, Bieschke J, Boeddrich A, Herbst M, Masino L, Lurz R, Engemann S, Pastore A, Wanker EE (2008) EGCG redirects amyloidogenic polypeptides into unstructured, offpathway oligomers. Nat Struct Mol Biol 15:558-566

15. Ferreira N, Cardoso I, Domingues MR, Vitorino R, Bastos M, Bai G, Saraiva MJ, Almeida MR (2009) Binding of epigallocatechin3 -gallate to transthyretin modulates its amyloidogenicity. FEBS Lett 19 583:3569-3576

16. Bieschke J, Russ J, Friedrich RP, Ehrnhoefer DE, Wobst H, Neugebauer K, Wanker EE (2010) EGCG remodels mature alpha-synuclein and amyloid-beta fibrils and reduces cellular toxicity. Proc Natl Acad Sci USA 107:7710-7715

17. Ferreira N, Saraiva MJ, Almeida MR (2012) Epigallocatechin-3gallate as a potential therapeutic drug for TTR-related amyloidosis: "in vivo" evidence from FAP mice models. PLoS ONE 7:e29933
18. Hunstein W (2007) Epigallocathechin-3-gallate in AL amyloidosis: a new therapeutic option? Blood 110:2216

19. Mereles D, Wanker EE, Katus HA (2008) Therapy effects of green tea in a patient with systemic light-chain amyloidosis. Clin Res Cardiol 97:341-344

20. Mereles D, Buss SJ, Hardt SE, Hunstein W, Katus HA (2010) Effects of the main green tea polyphenol epigallocatechin-3gallate on cardiac involvement in patients with $\mathrm{AL}$ amyloidosis. Clin Res Cardiol 99:483-490

21. Declaration of Helsinki (1967) Recommendations guiding doctors in clinical research. Adopted by the World Medical Association in 1964. Wiss Med J 66:25-26

22. Eriksson M, Buttner J, Todorov T, Yumlu S, Schonland S, Hegenbart U, Kristen AV, Dengler T, Lohse P, Helmke B, Schmidt $\mathrm{H}$, Rocken C (2009) Prevalence of germline mutations in the TTR gene in a consecutive series of surgical pathology specimens with ATTR amyloid. Am J Surg Pathol 33:58-65

23. Schroder R, Deckert M, Linke RP (2009) Novel isolated cerebral ALlambda amyloid angiopathy with widespread subcortical distribution and leukoencephalopathy due to atypical monoclonal plasma cell proliferation, and terminal systemic gammopathy. J Neuropathol Exp Neurol 68:286-299

24. Altland K, Benson MD, Costello CE, Ferlini A, Hazenberg BP, Hund E, Kristen AV, Linke RP, Merlini G, Salvi F, Saraiva MJ, Singer R, Skinner M, Winter P (2007) Genetic microheterogeneity of human transthyretin detected by IEF. Electrophoresis 28:2053-2064

25. Puille M, Altland K, Linke RP, Steen Muller MK, Kiett R, Steiner D, Bauer R (2002) 99mTc-DPD scintigraphy in transthyretin-related familial amyloidotic polyneuropathy. Eur J Nucl Med Mol Imaging 29:376-379

26. Rapezzi C, Quarta CC, Guidalotti PL, Pettinato C, Fanti S, Leone O, Ferlini A, Longhi S, Lorenzini M, Reggiani LB, Gagliardi C, Gallo P, Villani C, Salvi F (2011) Role of (99m)Tc-DPD scintigraphy in diagnosis and prognosis of hereditary transthyretinrelated cardiac amyloidosis. JACC Cardiovasc Imaging 4:659670

27. Gertz MA, Comenzo R, Falk RH, Fermand JP, Hazenberg BP, Hawkins PN, Merlini G, Moreau P, Ronco P, Sanchorawala V, Sezer O, Solomon A, Grateau G (2005) Definition of organ involvement and treatment response in immunoglobulin light chain amyloidosis (AL): a consensus opinion from the 10(th) International Symposium on Amyloid and Amyloidosis. Am J Hematol 79:319-328

28. Devereux RB, Alonso DR, Lutas EM, Gottlieb GJ, Campo E, Sachs I, Reichek N (1986) Echocardiographic assessment of left ventricular hypertrophy: comparison to necropsy findings. Am J Cardiol 57:450-458

29. Zile MR, Brutsaert DL (2002) New concepts in diastolic dysfunction and diastolic heart failure: Part I: diagnosis, prognosis, and measurements of diastolic function. Circulation 105:13871393

30. Lehrke S, Steen H, Kristen AV, Merten C, Lossnitzer D, Dengler TJ, Katus HA, Giannitsis E (2009) Serum levels of NT-proBNP as surrogate for cardiac amyloid burden: new evidence from gadolinium-enhanced cardiac magnetic resonance imaging in patients with amyloidosis. Amyloid 16:187-195

31. Henning SM, Niu Y, Liu Y, Lee NH, Hara Y, Thames GD, Minutti RR, Carpenter CL, Wang H, Heber D (2005) Bioavailability and antioxidant effect of epigallocatechin gallate administered in purified form versus as green tea extract in healthy individuals. J Nutr Biochem 16:610-616

32. Tanabe N, Suzuki H, Aizawa Y, Seki N (2008) Consumption of green and roasted teas and the risk of stroke incidence: results from the Tokamachi-Nakasato cohort study in Japan. Int J Epidemiol 37:1030-1040 
33. Lee SM, Kim CW, Kim JK, Shin HJ, Baik JH (2008) GCG-rich tea catechins are effective in lowering cholesterol and triglyceride concentrations in hyperlipidemic rats. Lipids 43:419-429

34. Sarma DN, Barrett ML, Chavez ML, Gardiner P, Ko R, Mahady GB, Marles RJ, Pellicore LS, Giancaspro GI, Low DT (2008) Safety of green tea extracts : a systematic review by the US Pharmacopeia. Drug Saf 31:469-484

35. Herlenius G, Wilczek HE, Larsson M, Ericzon BG (2004) Ten years of international experience with liver transplantation for familial amyloidotic polyneuropathy: results from the Familial Amyloidotic Polyneuropathy World Transplant Registry. Transplantation 77:64-71

36. Haagsma EB, Van Gameren II, Bijzet J, Posthumus MD, Hazenberg BP (2007) Familial amyloidotic polyneuropathy: long-term follow-up of abdominal fat tissue aspirate in patients with and without liver transplantation. Amyloid 14:221-226

37. Okamoto S, Yamashita T, Ando Y, Ueda M, Misumi Y, Obayashi K, Horibata Y, Uchino M (2008) Evaluation of myocardial changes in familial amyloid polyneuropathy after liver transplantation. Intern Med 47:2133-2137

38. Garcia-Herola A, Prieto M, Pascual S, Berenguer M, LopezViedma B, Mir J, Vilchez JJ, Berenguer J (1999) Progression of cardiomyopathy and neuropathy after liver transplantation in a patient with familial amyloidotic polyneuropathy caused by tyrosine-77 transthyretin variant. Liver Transpl Surg 5:246-248

39. Liepnieks JJ, Benson MD (2007) Progression of cardiac amyloid deposition in hereditary transthyretin amyloidosis patients after liver transplantation. Amyloid 14:277-282

40. Miyata M, Sato T, Kugimiya M, Sho M, Nakamura T, Ikemizu S, Chirifu M, Mizuguchi M, Nabeshima Y, Suwa Y, Morioka H, Arimori T, Suico MA, Shuto T, Sako Y, Momohara M, Koga T, Morino-Koga S, Yamagata Y, Kai H (2010) The crystal structure of the green tea polyphenol (-)-epigallocatechin gallate-transthyretin complex reveals a novel binding site distinct from the thyroxine binding site. Biochemistry 49:6104-6114

41. Ferreira N, Saraiva MJ, Almeida MR (2011) Natural polyphenols inhibit different steps of the process of transthyretin (TTR) amyloid fibril formation. FEBS Lett 585:2424-2430

42. Benson MD, Teague SD, Kovacs R, Feigenbaum H, Jung J, Kincaid JC (2011) Rate of progression of transthyretin amyloidosis. Am J Cardiol 108:285-289

43. Morner S, Hellman U, Suhr OB, Kazzam E, Waldenstrom A (2005) Amyloid heart disease mimicking hypertrophic cardiomyopathy. J Intern Med 258:225-230

44. Ng B, Connors LH, Davidoff R, Skinner M, Falk RH (2005) Senile systemic amyloidosis presenting with heart failure: a comparison with light chain-associated amyloidosis. Arch Intern Med 165:1425-1429

45. Rapezzi C, Merlini G, Quarta CC, Riva L, Longhi S, Leone O, Salvi F, Ciliberti P, Pastorelli F, Biagini E, Coccolo F, Cooke RM, Bacchi-Reggiani L, Sangiorgi D, Ferlini A, Cavo M, Zamagni E, Fonte ML, Palladini G, Salinaro F, Musca F, Obici L, Branzi A, Perlini S (2009) Systemic cardiac amyloidoses: disease profiles and clinical courses of the 3 main types. Circulation 120:1203-1212

46. Connors LH, Doros G, Sam F, Badiee A, Seldin DC, Skinner M (2011) Clinical features and survival in senile systemic amyloidosis: comparison to familial transthyretin cardiomyopathy. Amyloid 18(Suppl 1):152-154

47. Kristen AV, Haufe S, Schonland SO, Hegenbart U, Schnabel PA, Rocken C, Hardt S, Lohse P, Ho AD, Haberkorn U, Dengler TJ, Altland K, Katus HA (2011) Skeletal scintigraphy indicates disease severity of cardiac involvement in patients with senile systemic amyloidosis. Int J Cardiol Jul 15 [epub ahead of print]

48. Bellenger NG, Burgess MI, Ray SG, Lahiri A, Coats AJ, Cleland JG, Pennell DJ (2000) Comparison of left ventricular ejection fraction and volumes in heart failure by echocardiography, radionuclide ventriculography and cardiovascular magnetic resonance; are they interchangeable? Eur Heart J 21:1387-1396

49. Reichek N, Devereux RB, Rocha RA, Hilkert R, Hall D, Purkayastha D, Pitt B (2009) Magnetic resonance imaging left ventricular mass reduction with fixed-dose angiotensin-converting enzyme inhibitor-based regimens in patients with high-risk hypertension. Hypertension 54:731-737

50. Hughes DA, Elliott PM, Shah J, Zuckerman J, Coghlan G, Brookes J, Mehta AB (2008) Effects of enzyme replacement therapy on the cardiomyopathy of Anderson-Fabry disease: a randomised, double-blind, placebo-controlled clinical trial of agalsidase alfa. Heart 94:153-158

51. Sohns C, Sossalla S, Schmitto JD, Jacobshagen C, Raab BW, Obenauer S, Maier LS (2010) Visualization of transcoronary ablation of septal hypertrophy in patients with hypertrophic obstructive cardiomyopathy: a comparison between cardiac MRI, invasive measurements and echocardiography. Clin Res Cardiol 99:359-368

52. Yuan J, Qiao S, Zhang Y, You S, Duan F, Hu F, Yang W (2010) Follow-up by cardiac magnetic resonance imaging in patients with hypertrophic cardiomyopathy who underwent percutaneous ventricular septal ablation. Am J Cardiol 106:1487-1491

53. Prinz C, Farr M, Hering D, Horstkotte D, Faber L (2010) Reduction in ECG abnormalities and improvement of regional left ventricular function in a patient with Fabry's disease during enzyme-replacement therapy. Clin Res Cardiol 99:53-55

54. Weidemann F, Niemann M, Breunig F, Herrmann S, Beer M, Stork S, Voelker W, Ertl G, Wanner C, Strotmann J (2009) Longterm effects of enzyme replacement therapy on fabry cardiomyopathy: evidence for a better outcome with early treatment. Circulation 119:524-529

55. Al Zahrani GB, Bellavia D, Pellikka PA, Dispenzieri A, Hayman SR, Oh JK, Miyazaki C, Miller FA Jr (2009) Doppler myocardial imaging compared to standard two-dimensional and Doppler echocardiography for assessment of diastolic function in patients with systemic amyloidosis. J Am Soc Echocardiogr 22:290-298

56. Butz T, Piper C, Langer C, Wiemer M, Kottmann T, Meissner A, Plehn G, Trappe HJ, Horstkotte D, Faber L (2010) Diagnostic superiority of a combined assessment of the systolic and early diastolic mitral annular velocities by tissue Doppler imaging for the differentiation of restrictive cardiomyopathy from constrictive pericarditis. Clin Res Cardiol 99:207-215

57. Perdrix L, Mansencal N, Cocheteux B, Chatellier G, Bissery A, Diebold B, Mousseaux E, Abergel E (2011) How to calculate left ventricular mass in routine practice? An echocardiographic versus cardiac magnetic resonance study. Arch Cardiovasc Dis 104:343-351

58. Feng WY (2006) Metabolism of green tea catechins: an overview. Curr Drug Metab 7:755-809

59. Altland K, Schreiner R, Hunstein W (2009) Of Green Tea, Black Pepper, and Amyloidoses. www.ukgm.de/ugm_2/deu/ugi_hum/ EGCG_Piperin_engl.pdf

60. Suhr O, Danielsson A, Holmgren G, Steen L (1994) Malnutrition and gastrointestinal dysfunction as prognostic factors for survival in familial amyloidotic polyneuropathy. J Intern Med 235:479-485 